\title{
Overexpression of Gremlin 1 by sonic hedgehog signaling promotes pancreatic cancer progression
}

\author{
YONGTIAN YU ${ }^{1 *}$, LIANG CHENG $^{1 *}$, BIN YAN $^{1}$, CANCAN ZHOU $^{1}$, WEIKUN QIAN $^{1}$, YING XIAO $^{1}$, \\ TAO QIN $^{1}$, JUNYU CAO ${ }^{1}$, LIANG HAN ${ }^{1}$, QINGYONG MA ${ }^{1}$ and JIGUANG MA ${ }^{2}$ \\ Departments of ${ }^{1}$ Hepatobiliary Surgery and ${ }^{2}$ Anesthesiology, First Affiliated Hospital, \\ Xi'an Jiaotong University, Xi'an, Shaanxi 710061, P.R. China
}

Received March 6, 2018; Accepted June 18, 2018

DOI: 10.3892/ijo.2018.4573

\begin{abstract}
Sonic hedgehog (SHH) signaling is an important promotor of desmoplasia, a critical feature in pancreatic cancer stromal reactions involving the activation of pancreatic stellate cells (PSCs). Gremlin 1 is widely overexpressed in cancer-associated stromal cells, including activated PSCs. In embryonic development, $\mathrm{SHH}$ is a potent regulator of Gremlin 1 through an interaction network. This subtle mechanism in the cancer microenvironment remains to be fully elucidated. The present study investigated the association between Gremlin 1 and $\mathrm{SHH}$, and the effect of Gremlin 1 in pancreatic cancer. The expression of Gremlin 1 in different specimens was measured using immunohistochemistry. The correlations among clinicopathological features and levels of Gremlin 1 were evaluated. Primary human PSCs and pancreatic cancer cell lines were exposed to SHH, cyclopamine, GLI family zinc finger-1 (Gli-1) small interfering RNA (siRNA), and Gremlin 1 siRNA to examine their associations and effects using an MTT assay, reverse transcription-quantitative polymerase chain reaction analysis, western blot analysis, and migration or invasion assays. The results revealed the overexpression of Gremlin 1 in pancreatic cancer tissues, mainly in the stroma. The levels of Gremlin 1 were significantly correlated with survival rate and $\mathrm{pT}$ status. In addition, following activation of the PSCs, the expression levels of Gremlin 1 increased substantially. $\mathrm{SHH}$ acts as a potent promoter of the expression of Gremlin 1, and cyclopamine and Gli-1 siRNA modulated this effect. In a screen of pancreatic cancer cell lines, AsPC-1 and BxPC-3 cells expressed high levels of Gremlin 1, but only AsPC-1 cells exhibited a high expression level of SHH. The results of the indirect co-culture experiment suggested that paracrine $\mathrm{SHH}$
\end{abstract}

Correspondence to: Dr Jiguang Ma, Department of Hepatobiliary Surgery, First Affiliated Hospital, Xi'an Jiaotong University, 277 West Yanta Road, Xi'an, Shaanxi 710061, P.R. China

E-mail:jgma86@xjtu.edu.cn

*Contributed equally

Key words: Gremlin 1, sonic hedgehog signaling, pancreatic cancer, pancreatic stellate cell, progression from the AsPC-1 cells induced the expression of Gremlin 1 in the PSCs. Furthermore, Gremlin 1 siRNA negatively regulated the proliferation and migration of PSCs, and the proliferation, invasion and epithelial-mesenchymal transition of AsPC-1 and BxPC-3 cells. Based on the data from the present study, it was concluded that an abnormal expression level of Gremlin 1 in pancreatic cancer was induced by SHH signaling, and that the overexpression of Gremlin 1 enabled pancreatic cancer progression.

\section{Introduction}

Although substantial efforts have been made by medical scientists over several decades, pancreatic ductal adenocarcinoma (PDAC), which is currently the fourth most life-threatening type of cancer, remains a problem requiring a solution. Without effective early detection and desirable therapies, prognostic improvement for PDAC has not been achieved up until now. The relative 5 -year survival rate remains $<8 \%$, even in developed countries $(1,2)$. It is critical to further our understanding of the molecular mechanisms underlying pancreatic cancer in order to pinpoint promising targets for successful therapy. Gremlin 1, an antagonist of bone morphogenetic protein (BMP)2/4/7 (3), is expressed at high levels in pancreatic tumor niches and may be a potential therapeutic target.

Gremlin 1, in either its soluble or cell-associated form, is a highly conserved 184 -amino acid protein. This protein is also known as cell proliferation-inducing gene 2 protein (PIG-2), cysteine knot superfamily 1 BMP antagonist 1 , DAN domain family member (DAN)-2, downregulated in Mos-transformed cells protein, and increased in high glucose protein 2 (IHG-2) $(4,5)$. Together with DAN, Cerberus and Mucin 2, Gremlin 1 belongs to the Dan family, whose members share a conserved cysteine structure that includes a cysteine knot motif $(6,7)$. Of note, this feature is also present in transforming growth factor (TGF)- $\beta$ and vascular endothelial growth factor (VEGF), indicating that Gremlin 1 is a member of the TGF- $\beta$ superfamily. The human Gremlin 1 gene maps to chromosome 15q13-q15 (8). This gene was primarily segregated using a differential screen involving a transformation-resistant revertant of a v-mos-transformed rat fibroblast cell line, and its expression in adult rats appears to 
be associated with the final differentiation of cells in several organs $(8,9)$. The mRNA expression of human Gremlin 1 is widely observed in normal organs, including the small intestine, brain, colon, pancreas, ovary, prostate and skeletal muscle, and it appears to be expressed at high levels in specific types of cells, including neurons, astrocytes and fibroblasts $(8,10)$. Aberrant expression of Gremlin 1 is also found in malignancies. It has been demonstrated that the expression of Gremlin 1 is significantly higher in specimens of various types of cancer, specifically in the stroma in pancreatic, esophageal, colon, pulmonary, breast, and bladder cancer (11). However, the precise mechanism accounting for this widely confirmed character remains to be fully elucidated.

Sonic hedgehog ( $\mathrm{SHH})$ was originally identified as a factor that does not contribute to the normal development of the pancreas. The aberrant expression of SHH is associated with malignant diseases of the pancreas (12-15). SHH potently binds Patched (Ptch), a 12-pass transmembrane protein, which overrides the inhibitory effect of Ptch on Smoothened (SMO), another transmembrane protein. In a complex signaling cascade, GLI family zinc finger (Gli) $1 / 2 / 3$, transcription factors of $\mathrm{SHH}$, are activated and induce the activation of SHH target genes. SHH exhibits a multifunctional role in a paracrine manner in the tumor microenvironment (16). Several studies involving limb-bud development have revealed that fibroblast growth factor (FGF) $4 / 8$ triggers a reciprocal interaction network, which includes FGF4/8, SHH, BMP4 and Gremlin 1 (17-21). Regarding the correlation between Gremlin 1 and $\mathrm{SHH}$, there is merit in investigating their association in the pancreatic cancer niche.

Based on the findings of our previous studies on the SHH-associated tumor-stroma interaction in the pancreas $(14,22,23)$, the present study aimed to examine the association between SHH and Gremlin 1, and the contribution of the latter factor in the progression of pancreatic cancer. It was found that the overexpression of Gremlin 1 in malignant tissue was correlated with pT status and tumor-node-metastasis (TNM) stage. The SHH signal from tumor cells elevated the stromal expression of Gremlin 1, which contributed to the proliferation and migration of pancreatic stellate cells (PSCs). In addition, the proliferation, invasion, and epithelial to mesenchymal transition (EMT) of pancreatic cancer cells were promoted by Gremlin 1, which was promoted by $\mathrm{SHH}$ signaling in a ligand-independent manner. Taken together, the data suggested that Gremlin 1 was overexpressed in PDAC by SHH signaling to induce tumor progression.

\section{Materials and methods}

Patients and tissue samples and immunohistochemistry (IHC). Pancreatic cancer $(n=66)$ and normal $(n=7)$ tissue samples were obtained from the surgical pathology bank at the Department of Pathology, Shaanxi Provincial People's Hospital (Shaanxi, China), which comprised 39 cases (including four normal patients) and from the First Affiliated Hospital of Xi'an Jiaotong University (Xi'an, China), which comprised 27 cases (including three normal patients). The study was approved by the ethics committees of both organizations. Based on the 7th edition of the TNM classification of the American Joint Commission on Cancer (2010) (24), the pathologic TNM status of these specimens were evaluated. The tumor tissues were from 66 cases of Whipple resection for PDAC. The seven normal control specimens were derived from patients who had undergone partial pancreatectomy with benign diseases. Each patient signed an informed consent form. The clinicopathologic data are summarized in Table I. Follow-up data of all the cases were available, and the deadline was October 31, 2017. IHC analyses were performed with Gremlin 1 antibody (rabbit monoclonal antibody, 1:200 dilution; cat. no. ab22138; Abcam, Cambridge, MA, USA), according to the manufacturer's instructions using a SABC kit (Maxim, Fuzhou, China). The samples were incubated with the primary antibody at $4^{\circ} \mathrm{C}$ overnight and with secondary antibodies (SP-9001; Beijing Zhongshan Golden Bridge Biotechnology Co., Ltd., Beijing, China). Following immunohistochemical procedures, the slides were stained with the 3,3'-diaminobenzidine (DAB) liquid chromogen substrate kit (ZLI-9017; Beijing Zhongshan Golden Bridge Biotechnology Co., Ltd.) and counterstained with hematoxylin. Finally, the results of IHC were observed under a microscope (SCN 400; Leica Microsystems GmbH, Mannheim, Germany). The protein expression was evaluated in four grades as follows: 0 (negative), 1 (weak), 2 (medium), and 3 (strong). Based on the percentage of positive staining area relative to the total tumor area, the extent of staining was classified into four grades as follows: $0(0 \%), 1(1-10 \%)$, $2(11-50 \%), 3(51-80 \%)$ and $4(>81 \%)$. The overall expression score was equal to the sum of the expression grade and the extent grade.

Cancer cell culture. In the present study, the origin of the human pancreatic cancer cell lines (AsPC-1 and BxPC-3) was the American Type Culture Collection (Manassas, VA, USA), as described previously (14), wich were purchased from the Shanghai Institutes for Biological Sciences, Chinese Academy of Sciences (Shanghai, China). The general culture conditions for all tumor cell lines was $37^{\circ} \mathrm{C}$ with a $5 \% \mathrm{CO}_{2}$ atmosphere in DMEM containing 10\% FBS (both from HyClone; GE Healthcare Life Sciences, Logan, UT, USA) and $1 \%$ penicillin and streptomycin. As described by Li et al, the cells were exposed to SHH and/or in different conditions (14). The cells $\left(1 \times 10^{5} / \mu \mathrm{l}\right)$ were cultured under standard conditions in a $5 \% \mathrm{CO}_{2}$ atmosphere at $37^{\circ} \mathrm{C}$ for $72 \mathrm{~h}$ and exposed to SHH, cyclopamine, Gli-1 small interfering RNA (siRNA) and Gremlin 1 siRNA (to avoid confusion, details of different conditions are shown in the Results section, separately).

Quantification of SHH in conditioned medium (CM). According to the manufacturer's protocol of the enzymelinked immunosorbent assay (ELISA) kit (R\&D Systems, Inc., Minneapolis, MN, USA), the SHH concentrations in the CM of the pancreatic cancer cells and PSCs were quantified.

Isolation and culture of human PSCs. According to the methods described by Vonlaufen et al (25) and our previous study $(14,26)$, human PSCs were isolated from the normal pancreatic tissue samples that were obtained from patients who underwent partial pancreatectomy with benign disease at Shaanxi Provincial People's Hospital and the First Affiliated Hospital of Xi'an Jiaotong University. The cell culture conditions were $37^{\circ} \mathrm{C}$ with $5 \% \mathrm{CO}_{2}$ in DMEM/F12 
Table I. Statistical association between the expression of Gremlin 1 and clinicopathological features in 66 cases of pancreatic ductal adenocarcinoma.

\begin{tabular}{|c|c|c|c|c|}
\hline \multirow[b]{2}{*}{ Feature } & \multirow[b]{2}{*}{ Cases, (n) } & \multicolumn{2}{|c|}{ Gremlin 1} & \multirow[b]{2}{*}{ P-value ${ }^{a}$} \\
\hline & & Normal expression, n (\%) & Overexpression, n (\%) & \\
\hline Sex & & & & 0.603 \\
\hline Male & 41 & $14(34.1)$ & $27(65.9)$ & \\
\hline Female & 25 & 7 (28.0) & $18(72.0)$ & \\
\hline Mean age (years) & & & & 0.336 \\
\hline$\leq 58.88$ & 32 & $12(37.5)$ & $20(62.5)$ & \\
\hline$>58.88$ & 34 & $9(26.5)$ & $25(73.5)$ & \\
\hline Histological grade & & & & 0.155 \\
\hline 1 & 35 & $14(40.0)$ & $21(60.0)$ & \\
\hline 2 & 20 & $6(30.0)$ & $14(70.0)$ & \\
\hline 3 & 11 & $1(9.1)$ & $10(90.9)$ & \\
\hline pT status & & & & $0.009^{\mathrm{b}}$ \\
\hline 1 & 8 & $6(75.0)$ & $2(25.0)$ & \\
\hline 2 & 19 & $8(42.1)$ & $11(57.9)$ & \\
\hline 3 & 31 & $5(16.1)$ & 26 (83.9) & \\
\hline 4 & 8 & $2(25.0)$ & $6(75.0)$ & \\
\hline $\mathrm{pN}$ status & & & & 0.107 \\
\hline 0 & 41 & $16(39.0)$ & $25(61.0)$ & \\
\hline 1 & 25 & $5(20.0)$ & $20(80.0)$ & \\
\hline pM status & & & & 0.151 \\
\hline 0 & 57 & $20(35.1)$ & 37 (64.9) & \\
\hline 1 & 9 & $1(11.1)$ & $8(88.9)$ & \\
\hline TNM stage & & & & $0.029^{\mathrm{b}}$ \\
\hline I & 24 & $13(54.2)$ & $11(45.8)$ & \\
\hline II & 28 & $6(21.4)$ & $22(78.6)$ & \\
\hline III & 5 & $1(20.0)$ & $4(80.0)$ & \\
\hline IV & 9 & $1(11.1)$ & $8(88.9)$ & \\
\hline
\end{tabular}

${ }^{\mathrm{a}} \chi^{2}$ test; ${ }^{\mathrm{b}} \mathrm{P}<0.05$ was considered to indicate a statistically significant difference. TNM, tumor-node-metastasis (American Joint Commission on Cancer).

media supplemented with $10 \%$ heat-inactivated FBS (both from HyClone; GE Healthcare Life Sciences), together with $1 \%$ penicillin and streptomycin. Several methods, including Oil Red O staining of the fat droplets in the cytoplasm and immunofluorescence of $\alpha$-smooth muscle actin ( $\alpha$-SMA). Oil Red O staining was applied to visualize intracellular lipid content in PSCs. Briefly, PSCs on the slides were washed with phosphate-buffered saline (PBS) and fixed in 4\% paraformaldehyde for $1 \mathrm{~h}$ at room temperature. After washing the PSCs with isopropanol, pre-warmed $0.25 \%$ Oil Red O working solution was used to stain intracellular lipid content for $15 \mathrm{~min}$ in a $60^{\circ} \mathrm{C}$ oven. After being washed with PBS twice, the cells were re-stained with hematoxylin for $15 \mathrm{sec}$ and sealed with glycerin on glass slides. Finally, a light microscope (Nikon Eclipse Ti-S; Nikon, Tokyo, Japan) at a magnification of x200 was used to photograph the cells stained with Oil Red O. After the designated treatment, PSCs were fixed with $4 \%$ paraformaldehyde for $10 \mathrm{~min}$ at room temperature, permeabilized in
$0.5 \%$ Triton $\mathrm{X}-100$ for $10 \mathrm{~min}$, and blocked in $1 \% \mathrm{BSA}$ for $1 \mathrm{~h}$. Fixed cells were then incubated with $\alpha$-SMA antibodies at 1:100 dilution at $4^{\circ} \mathrm{C}$ overnight. Cells were washed and incubated with Goat anti-rabbit FITC (green) IgG antibody (ZSGB-BIO Inc., Beijing, China) at 1:100 dilution for $60 \mathrm{~min}$. Nuclei were stained with DAPI for $5 \mathrm{~min}$. The cells were visualized by a fluorescent microscope (Nikon) using appropriate excitation and emission spectra at a $\mathrm{x} 400$ magnification) were used to confirm the PSCs.

Cell proliferation assay. The cancer cells and PSCs were seeded into 96-well culture plates at a density of 2,000-5,000 cells per well. First, the cells were starved for $24 \mathrm{~h}$, and they were then cultured in specific media [according to given concentrations of cyclopamine and SHh, the drugs (or solvent only) were administered in medium containing $1 \%$ FBS] separately. At 24, 48, 72, or $96 \mathrm{~h}$ following removal of the media, the optical densities at $492 \mathrm{~nm}$ were monitored 
with 3-(4,5-dimethylthiazolyl-2)-2,5-diphenyltetrazolium bromide (MTT) reagent using a multifunction microplate reader (POLARstar OPTIMA; BMG Labtech, Offenburg, Germany).

Indirect co-culture of pancreatic cancer cells and PSCs. Prior to the media being replaced with DMEM supplemented with $2 \%$ FBS and $1 \%$ penicillin and streptomycin, $10 \%$ FBS was added to the cultured pancreatic cancer cells until they reached $50 \%$ confluence. After $48 \mathrm{~h}$, the CM were collected and incubated with the PSCs for $72 \mathrm{~h}$. The cells $\left(1 \times 10^{6} / \mathrm{ml}\right)$ were cultured under standard conditions with a $5 \% \mathrm{CO}_{2}$ atmosphere at $37^{\circ} \mathrm{C}$.

Cell migration and invasion assays. For the assessment of cell migration and invasion, wound-healing and Transwell migration assays were performed based on the protocol described in our previous study (14).

RT-qPCR assay. According to the methods previously described (14), an RT-qPCR assay was performed. The extraction of the total ribonucleic acid (RNA) was achieved using the Fastgen1000 RNA isolation system (Fastgen, Shanghai, China) according to the manufacturer's instructions. A Prime Script RT reagent kit (Takara, Dalian, China) was used to reverse-transcribe the total RNA into cDNA. Quantitative (real-time) PCR was performed as previously described (27). The PCR primer sequences used were as follows: $\mathrm{H}-\beta$-actin forward, 5 -AGC TACGAGCTGCCTGACG-3' and reverse, 5'-GCATTTGCG GTGGACGAT-3'; H-Gremlin 1 forward, 5'-AACTACAGCCAC CTACCAAG-3' and reverse, 5'-CACGAACTACGCACAAG CAG-3'; R-Gremlin 1 forward, 5'-ACTGTGCTTCAGATGGT CGG-3' and reverse, 5'-AATGCGGCCCTCAGAGTTAC-3'; H-SHH forward, 5'-GCGACTTCCTCACTTTCCTG-3' and reverse, 5'-CCGGTTGATGAGAATGGTG-3'; R-SHH forward, 5'-TATGAGGGTCGAGCAGTGGA-3' and reverse, 5'-CGGGACGTAAGTCCTTCACC-3'. The expression level of each target gene was determined using $\beta$-actin as the normalization control. The relative gene expression was calculated using the $2^{-\Delta \Delta C q}$ method (28).

Western blot analysis. As previously described (29), primary antibodies were obtained from different sources as follows: $\alpha$-SMA (1:1,000 dilution; goat polyclonal antibody; cat. no. ab21027) antibody was provided by Abcam, and $\mathrm{N}$-cadherin, E-cadherin, Snail and Vimentin antibodies were provided by Cell Signaling Technology, Inc., Danvers, MA, USA (1:1,000 dilution; cat. no. 9782). The secondary antibodies (1:10,000 dilution; goat anti-rabbit IgG; cat. no. ab6721) and anti-mouse $\operatorname{IgG}$ (1:10,000 dilution; rabbit anti-mouse HRP; cat. no. ab6728) were provided by Abcam. Whole-cell lysates of the AsPc-1 and BxPC-3 cells were prepared by using the RIPA buffer (Beyotime, Guangzhou, China) according to the manufacturer's instructions. Then, the concentration was determined via a BCA protein assay kit (Pierce, Rockford, IL, USA). The protein lysates were subsequently resolved on a $10 \%$ polyacrylamide gel with a 5\% stacking gel. Next, the proteins were blotted on polyvinylidene difluoride membranes. Before incubating with the primary antibodies overnight at $4^{\circ} \mathrm{C}$, the membranes were blocked for $2 \mathrm{~h}$ in TBS containing $0.1 \%$ (vol/vol) Tween-20 and 10\% (wt/vol) non-fat dry milk powder. Following the incubation of the secondary HRP-coupled antibodies for $2 \mathrm{~h}$ at room temperature, the membranes were washed via $0.1 \% \mathrm{TBS} /$ Tween-20, and the signal was detected using the enhanced chemiluminescence kit and a Molecular Imager ChemiDoc XRS System (Bio-Rad Laboratories, Hercules, CA, USA).

RNA interference. The siRNA for Gremlin 1 (GREM1Homo-482, forward, 5'-GCAACAGUCGCACCAUCAUTT-3' and reverse, 5'-AUGAUGGUGCGACUGUUGCTT-3'), siRNA for GLI1 (GLI1-Homo-2758, forward, 5'-GGCUCAGCUUG UGUGUAAUTT-3' and reverse, 5'-AUUACACACAAGCUG AGCCTT-3'), and negative control siRNA (NC, forward, 5'-GUA UGACAACAGCCUCAAGTT-3' and reverse, 5'-CUUGAG GCUGUUGUCAUACTT-3') were provided by GenePharm (Shanghai, China). Using Lipofectamine RNAi MAX reagent (Invitrogen; Thermo Fisher Scientific, Inc.), the PSCs or pancreatic cancer cells $\left(2 \times 10^{5} /\right.$ well in 6-well plates) were transfected with $100 \mathrm{nM}$ siRNA, based on the previously reported protocol (30). After $48 \mathrm{~h}$, the transfected cells were collected for further analysis.

Statistical analysis. Data are expressed as the mean \pm standard deviation. Statistical analysis of the human tissue data was performed using Pearson's $\chi^{2}$ test. The in vitro and in vivo data were assessed using one-way analysis of variance for multiple comparisons between the groups with the S-N-K method as a post hoc test. The SPSS statistical software package (version 19.0; IBM SPSS, Armonk, NY, USA) was used to perform the statistical tests. $\mathrm{P}<0.05$ was considered to indicate a statistically significant difference.

\section{Results}

Gremlin 1 is overexpressed in pancreatic cancer tissue and correlates with poor clinical prognosis. To elucidate the patterns of Gremlin 1 expression in normal and malignant pancreas tissue, specimens from 73 patients, including seven normal cases and 66 malignant cases, were analyzed. According to the methods described above, the expression of Gremlin 1 was categorized into four staining levels as follows: Negative, weak, moderate and strong. The normal pancreatic tissues were mainly negative for the expression of Gremlin 1. Correspondingly, its expression was positive in 45/66 cancer cases, including weak in 18 cases, moderate in 15 cases and strong in 12 cases.

In 38/45 cases, the IHC staining confirmed extensive staining of Gremlin 1 in the cancer stroma. However, in the remaining seven cases, Gremlin 1 was predominantly expressed in the cancer parenchyma (Fig. 1A). These data indicated that Gremlin 1 may be functional in cancer cells and stroma cells. In addition, the associations among the clinicopathological features and expression of Gremlin 1 were analyzed in the PDAC specimens, which are summarized in Table I. Notably, the correlation analysis showed that the total Gremlin 1 expression was positively associated with the pT status. Specifically, the expression of Gremlin 1 was detected in $2 / 8$ pT1 cases (25\%), 11/19 pT2 cases (57.9\%), 26/31 pT3 cases $(83.9 \%)$, and $6 / 8$ pT4 cases $(75.0 \%)$. The associations between sex, age, and histological grade and the staining 

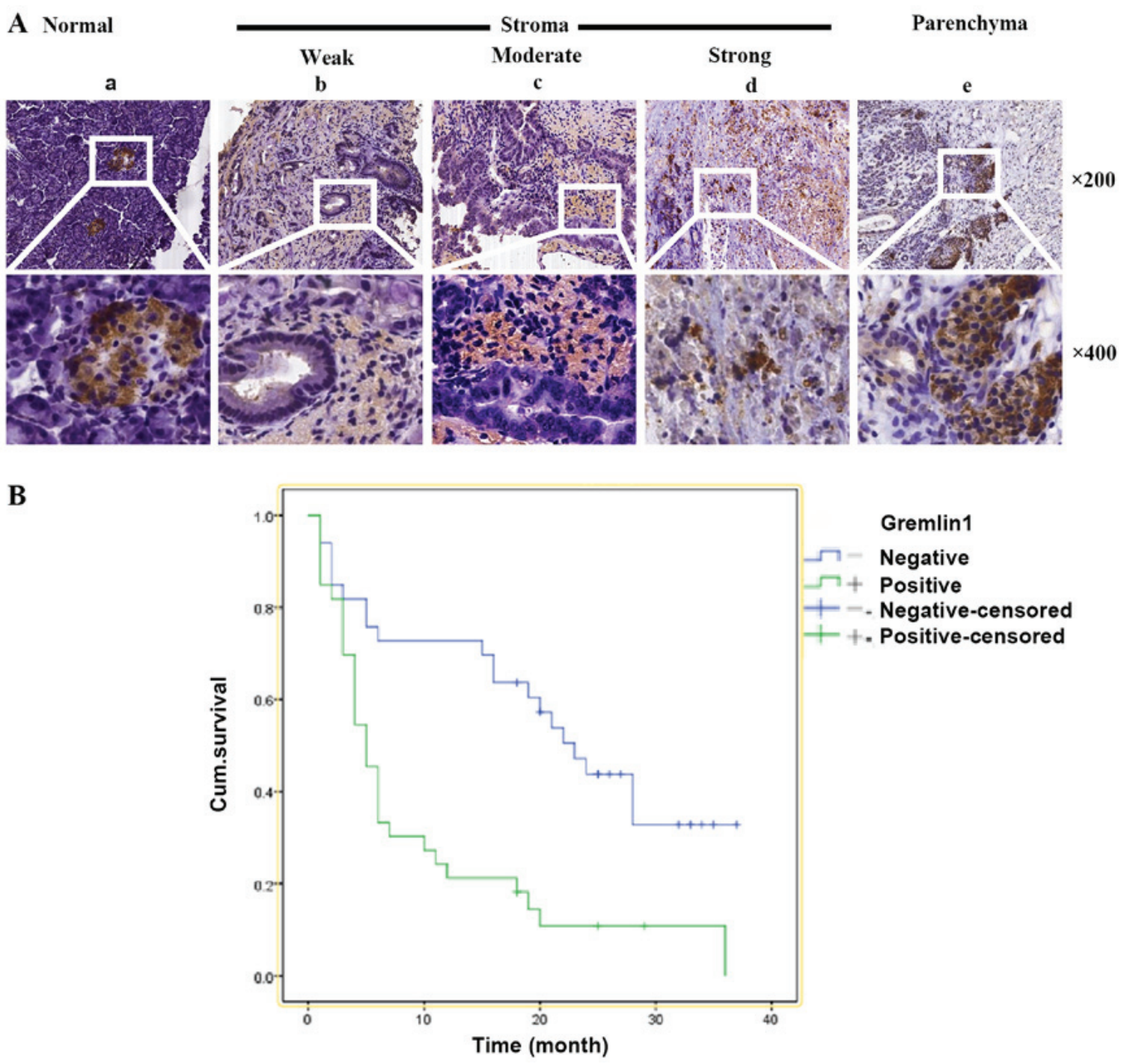

Figure 1. Gremlin 1 is overexpressed in pancreatic cancer tissue and correlates with poor clinical prognosis. (A) Representative images of the staining of Gremlin 1. (a) In the normal pancreas, Gremlin 1 was mainly negative. Immunohistochemistry staining of Gremlin 1 in the pancreatic cancer stroma was (b) weak, (c) moderate and (d) strong. (e) Aberrant expression of Gremlin 1 was present in the cancer parenchyma. (B) Kaplan-Meier survival curve of the Gremlin 1-positive and Gremlin 1-negative groups $(\mathrm{P}<0.05)$.

level of Gremlin 1 were also analyzed, however, there were no statistically significant associations.

Kaplan-Meier survival analysis was performed, and it was found that the median survival rate of the Gremlin 1-positive and Gremlin 1-negative groups were 9.5 and 21.7 months, respectively (Fig. 1B). These findings indicated that Gremlin 1 may be involved and be a valuable biomarker in PDAC.

Paracrine SHH signaling by pancreatic cancer cells regulates the expression of Gremlin 1 in PSCs. To detect the role of Gremlin 1 in the pancreatic cancer microenvironment, the expression of Gremlin 1 in PSCs was first investigated. Gremlin 1 was undetected in quiescent PSCs. However, in activated PSCs, the expression of Gremlin 1 increased with culture duration and this was marked. At 1 week following isolation of the PSCs, a high level of Gremlin 1 was observed in the activated PSCs (Fig. 2A). It was also found that two pancreatic cancer cell lines (AsPc-1 and BxPc-3) overexpressed Gremlin 1, whereas the other three pancreatic cancer cell lines (CFPAC, Panc-1 and SW1990) exhibited low expression levels of Gremlin 1 (Fig. 2B).
As reported in our previous study (14), SHH is important in promoting the activation of PSCs. The present study further examined the variance in the expression of Gremlin 1 in PSCs under the influence of SHH. The effect of recombinant human (rh)SHH on quiescent PSCs was investigated, and it was observed that Gremlin 1 was upregulated following $24 \mathrm{~h}$ of treatment (Fig. 2C). This elevation was more marked than in the self-activated PSCs (Fig. 2A). However, such promotion was shut down by cyclopamine, a special inhibitor of $\mathrm{SHH}$ signaling, via the direct inhibition of SMO in a dose-dependent manner (Fig. 2C).

According to a previous study (14), high levels of SHH are found in the AsPC-1 culture medium, whereas low levels are found in BxPC-3 culture medium. This finding was confirmed by an ELISA assay in the present study (Fig. 2D). Therefore, the culture supernatants of the AsPC-1 cells were collected following $48 \mathrm{~h}$ of culture and were used in an indirect co-culture system of PSCs and pancreatic cancer cells. As a result, the supernatants of the AsPC-1 cells promoted the expression of Gremlin 1 in the PSCs, and cyclopamine exerted 
A

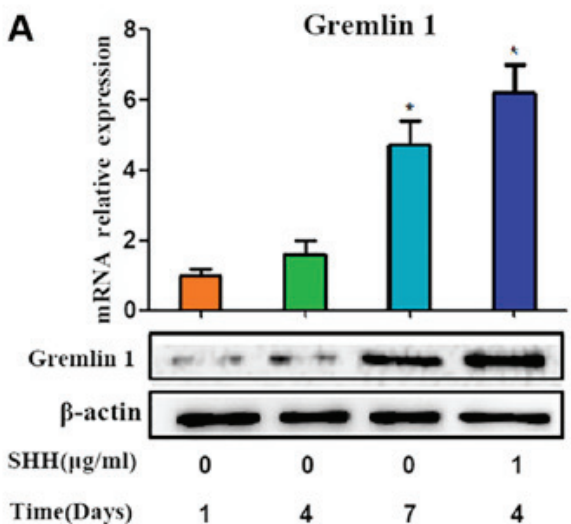

C
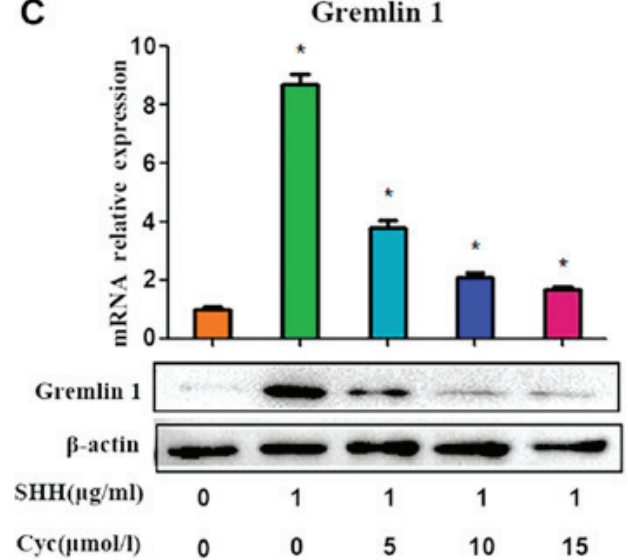

$\mathrm{E}$
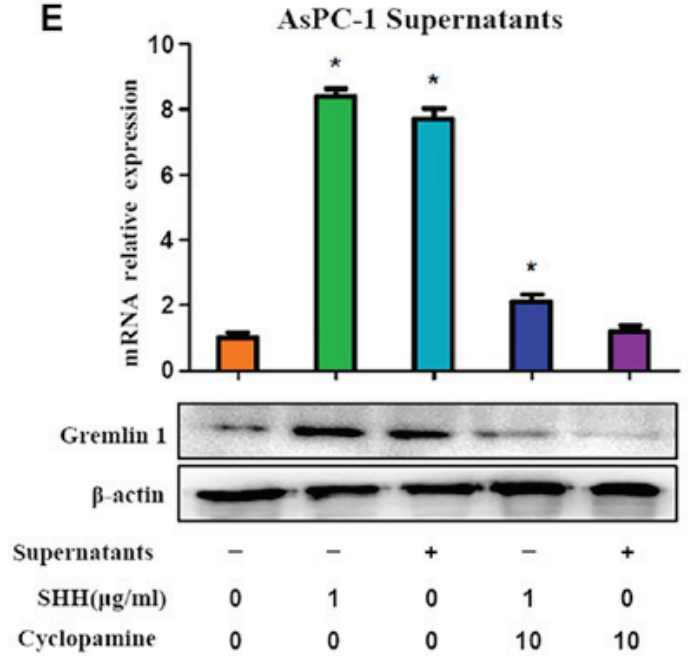

B

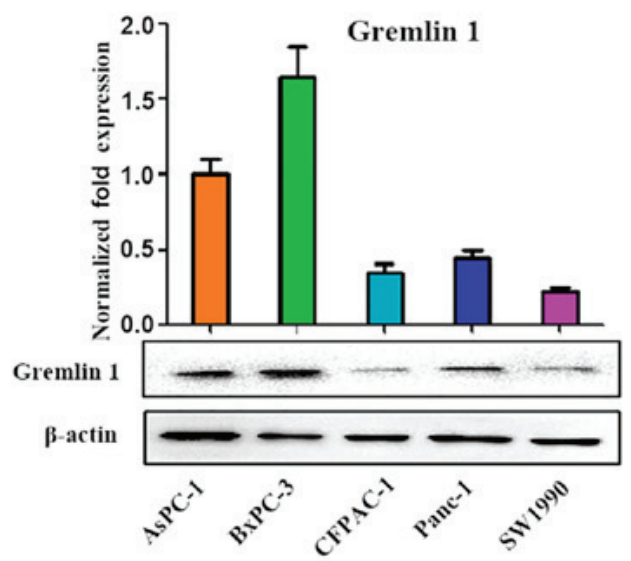

D

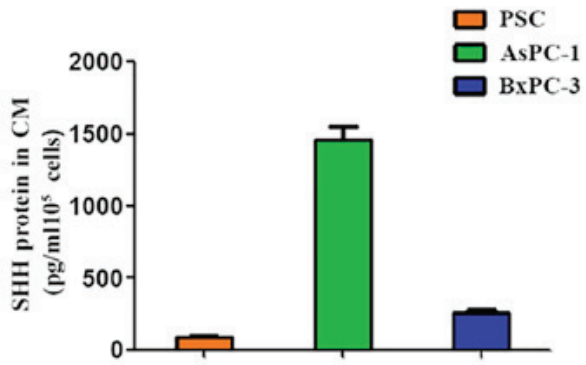

$\mathbf{F}$
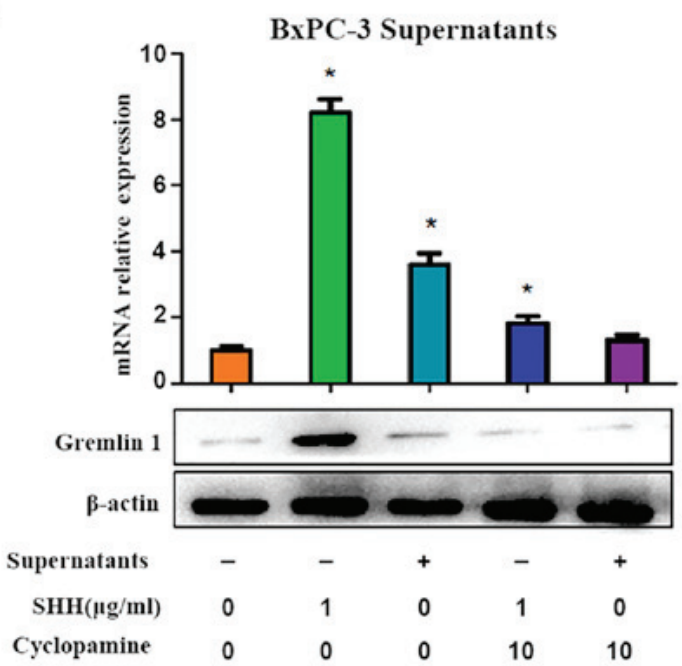

Figure 2. Paracrine SHH signaling by pancreatic cancer cells regulates the expression of Gremlin 1 in PSCs. (A) Variance in expression of Gremlin 1 during PSC self-activation and the upregulation of SHH. "P<0.05 compared to the group on day 1. (B) Expression of Gremlin 1 in five pancreatic cancer cell lines. (C) SHH elevated the expression of Gremlin 1, whereas cyclopamine inhibited the expression of Gremlin 1 in a dose-dependent manner in PSCs. (D) Enzymelinked immunosorbent assay analysis of SHH concentrations in the culture medium of PSCs, AsPC-1 and BxPC-3 cells. Effects of the culture supernatants of (E) AsPC-1 and (F) BxPC-3 cells, in contrast to the regulation of SHH and cyclopamine, on the expression of Gremlin 1 in the PSCs. "P<0.05 compared to the untreated group. SHH, sonic hedgehog; PSCs, pancreatic stellate cells; CM, conditioned medium.

a negative effect in a dose-dependent manner (Fig. 2E). However, such marked variances were not observed in the BxPC-3 groups (Fig. 2F). These results indicated that SHH signaling was crucial for the modulation of Gremlin 1 in PSCs.

Silencing of Gli-1 impedes the expression of Gremlin 1 in pancreatic cancer cells and PSCs. Based on the above findings, the effects of rh-SHH and cyclopamine were examined in
AsPC-1 and BxPC-3 cells (Fig. 3A and B). However, no significant change in the expression of Gremlin 1 was observed under the influence of rh-SHH in either of the two tumor cell lines, whereas cyclopamine exerted a negative effect on the expression of Gremlin 1 in these cancer cells (Fig. 3A and B). In addition, the expression of Gremlin 1 was suppressed by Gli-1 siRNA (Fig. 3C-E). According to a previous study, in certain situations, cyclopamine and Gli-1, the critical 
A

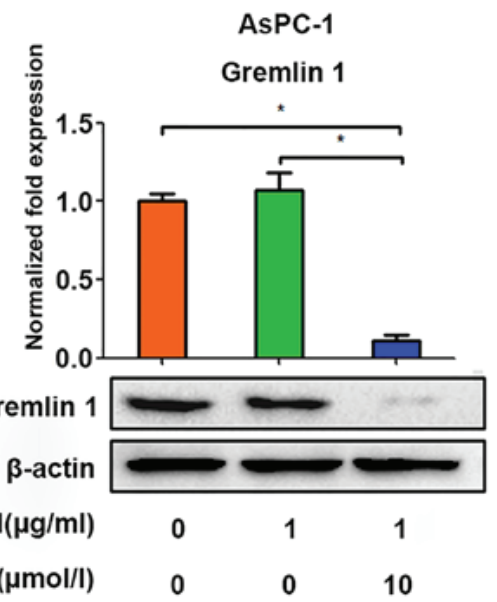

C

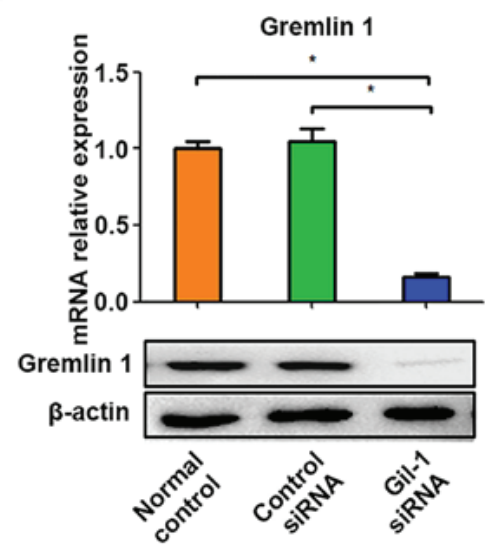

B

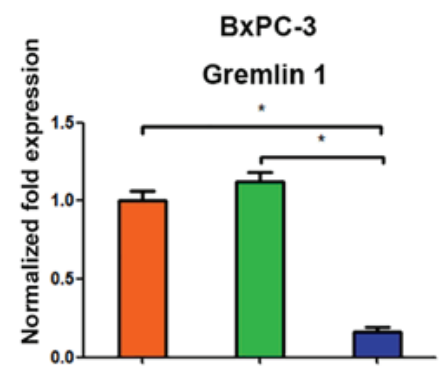

Gremlin 1

$\beta$-actin

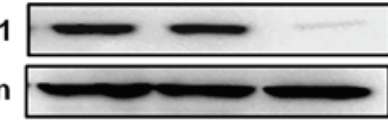

$\begin{array}{llll}\mathrm{SHH}(\mu \mathrm{g} / \mathrm{ml}) & 0 & 1 & 1\end{array}$

$\begin{array}{llll}\mathrm{Cyc}(\mu \mathrm{mol} / \mathrm{l}) & 0 & 0 & 10\end{array}$

D

BXPC-3

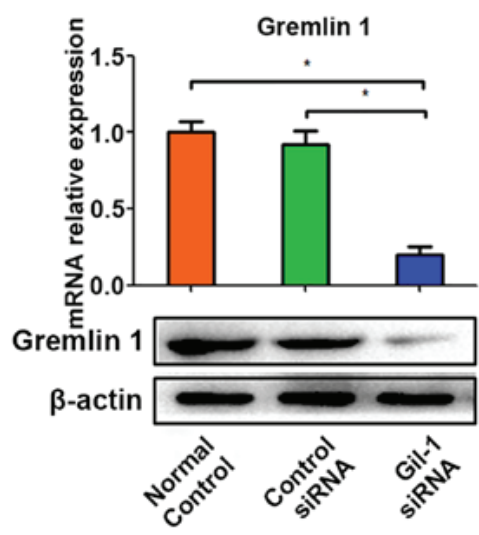

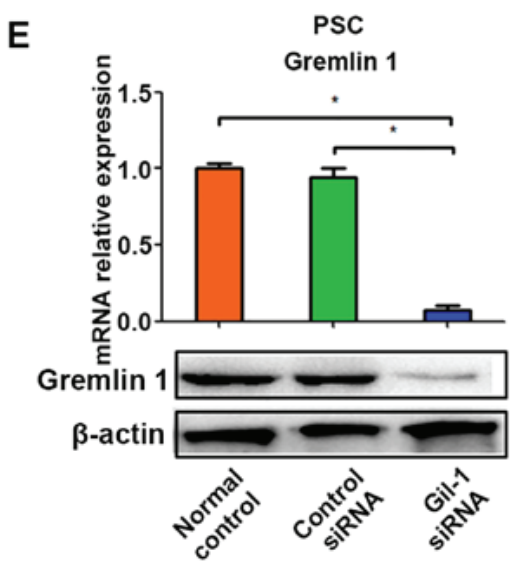

Figure 3. Silencing Gli-1 inhibits the expression of Gremlin 1 in pancreatic cancer cells and PSCs. Cyclopamine, unlike SHH ligand, was a potent inhibitor of Gremlin 1 science in the (A) AsPC-1 and (B) BxPC-3 cells pancreatic cancer cells. " $\mathrm{P}<0.05$ compared to the untreated group. Gli-1 siRNA potently downregulated Gremlin 1 in the (C) AsPC-1 and (D) BxPC-3cancer cells and (E) PSCs. "P<0.05 compared to the normal control group. SHH, sonic hedgehog; PSCs, pancreatic stellate cells; Gli-1, GLI family zinc finger-1; siRNA, small interfering RNA.

downstream factors of SHH, are involved in SHH signaling in pancreatic cancer cells in a ligand-independent manner (29). Therefore, the present study investigated whether Gli-1 siRNA modulated the expression of Gremlin 1 in cancer cells. It was observed that the silencing of Gli-1 restricted the expression of Gremlin 1 in the AsPC-1 and BxPC-3 cells (Fig. 3C and D). The above data indicated that the expression of Gremlin 1 in pancreatic tumor cells may be modulated by SHH indirectly, which depends on the activation of Gli-1 rather than the SHH ligand.
Variability in the expression of Gremlin 1 induced by SHH signaling modulates the proliferation of pancreatic cancer cells and PSCs. To further uncover the functional relevance of Gremlin 1 in PSCs, MTT assays were performed, which demonstrated that Gremlin 1 siRNA significantly decreased the proliferation ability of PSCs. Cyclopamine also resulted in a negative effect. Furthermore, although SHH increased the growth of the PSCs, it was found that either Gremlin 1 siRNA or cyclopamine attenuated this positive effect. However, no statistically significant difference was observed among the 

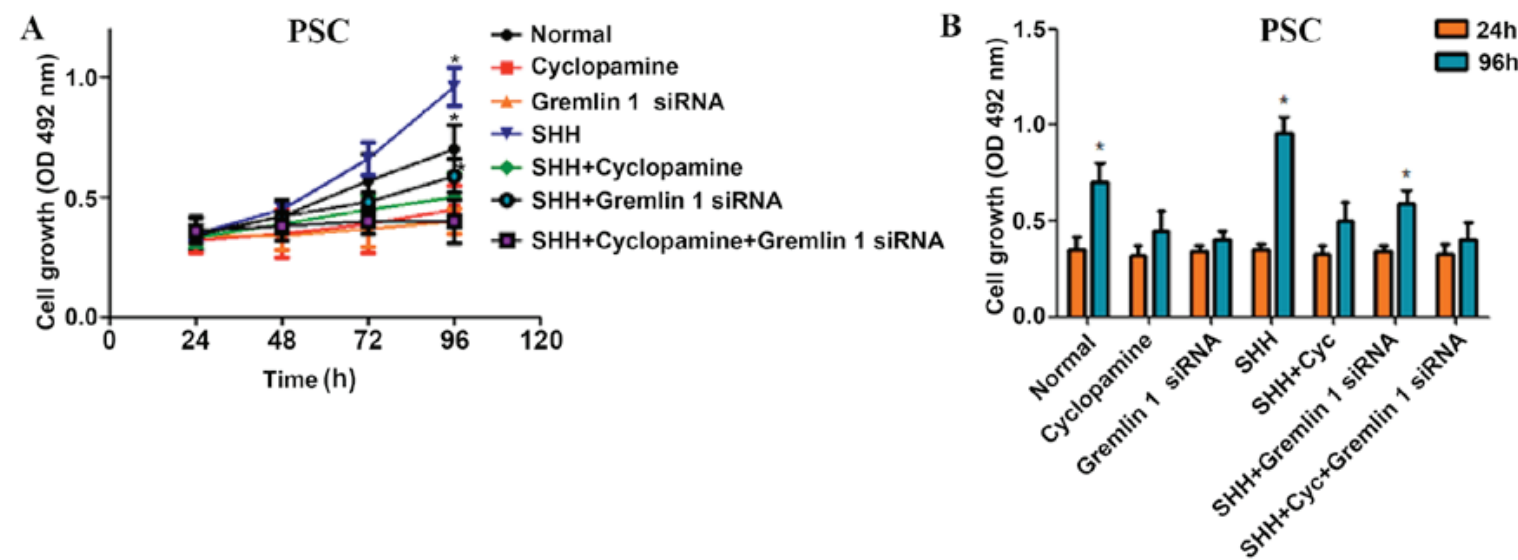

C

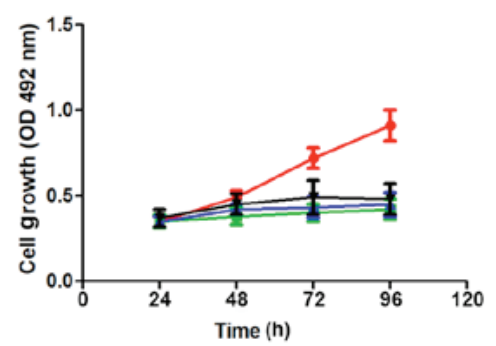

D

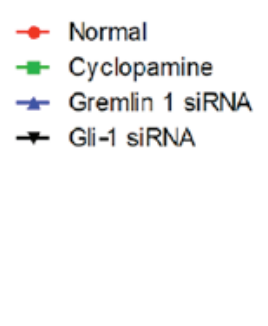

BxPC-3

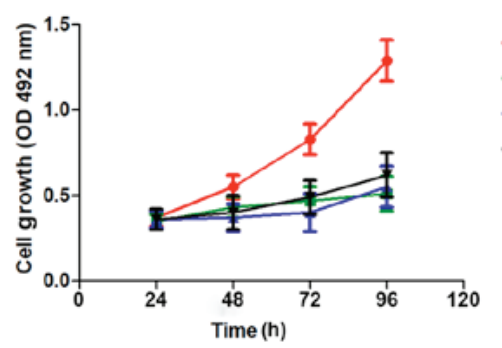

Figure 4. Variability of the expression of Gremlin 1 induced by SHH signaling modulates the proliferation of pancreatic cancer cells and PSCs. Effects of Gremlin 1 siRNA, SHH, cyclopamine, and Gli-1 siRNA on the proliferation of PSCs (A) over time and (B) compared between and 24 and 96 h. Effects of Gremlin 1 siRNA, cyclopamine, and Gli-1 on the proliferation of (C) AsPC-1 and (D) BxPC-3 cells. * P $<0.05$, compared with control group. SHH, sonic hedgehog; PSCs, pancreatic stellate cells; Gli-1, GLI family zinc finger-1; siRNA, small interfering RNA; OD, optical density.

remaining groups (Fig. 4A and B). The cell proliferation assay revealed that the growth of the AsPC- 1 and $\mathrm{BxPC}-3$ cells was inhibited by silencing Gremlin 1. However, this inhibition was not significantly different from that of cyclopamine or Gli-1 siRNA (Fig. 4C and D).

Overexpression of Gremlin 1 induced by SHH signaling promotes the invasion and migration ability of pancreatic cancer cells in vitro. The findings from the above experiments revealed that Gremlin 1 may have an active role in cancer cells. Therefore, wound-healing migration assays and Transwell invasion assays were performed using AsPC-1 and BxPC-3 cells in different conditions.

In the Transwell invasion assays, it was found that Gremlin 1 siRNA and cyclopamine inhibited the aggression of the cancer cells. In accordance with the negative effects on the AsPC-1 cells, no significant difference was observed in the Gremlin 1 siRNA + cyclopamine group, compared with the siRNA group, and cyclopamine group. For the BxPC-3 cells, the downregulation of Gremlin 1 not only significantly decreased the invasion of the siRNA group but also inhibited that of the cyclopamine group (Fig. 5A and B). To quantify the migration ability of the PSCs, a wound-induced migration assay was performed. As shown in Fig. 5C and D, a positive effect was observed in the SHH group, which was suppressed by cyclopamine, whereas the siRNA groups had a negative effect. However, no statistically significant difference was observed between the Gremlin 1 siRNA and cyclopamine groups (Fig. 5C and D). These data indicated that Gremlin 1 siRNA and cyclopamine may share a similar mechanism in their inhibition of PSC proliferation and migration.
Subsequently, markers of EMT, namely, E-cadherin, vimentin, N-cadherin, and Snail, were examined the silencing of Gremlin 1 resulted in suppression of the expression of E-cadherin and elevation in the expression of the other three proteins (Fig. 5E and F). The above data suggested that Gremlin 1 is a promoter of pancreatic cancer cell invasion, migration and EMT.

\section{Discussion}

Accumulating evidence supports the tumor promoting role of Gremlin 1. The available microarray data in the Oncomine database further confirms that the expression of Gremlin 1 is substantially upregulated in tumor specimens compared with that in normal samples (31-33). According to studies by Sneddon et al and Namkoong et al $(11,34)$, the overexpression of Gremlin 1 is observed in diverse human tumors and typically has an oncogenic role in malignancies of the pancreas, cervix, ovary, kidney, lung, sarcoma, colon and breast. Notably, in a study of 165 pancreas specimens, the RNA levels of Gremlin 1 increased consistently from $5 \%$ in normal tissue to $>70 \%$ in malignant tissue (11). This finding was further confirmed by experiments in a study by Segara et al (31). As its other name, PIG-2, indicates, Gremlin 1 is overexpressed in various malignancies (tumor and stromal cells) and promotes tumor cell proliferation (35). As BMP4 inhibits the growth of tumor cells and BMPs may act as inhibitors of carcinogenesis and recurrence (36), Gremlin 1 may effectively reverse their effects. Another mechanism may involve the downregulation of cell cycle inhibitor p27kip1, the hyperphosphorylation of Retinoblastoma protein and the activation of E2F (37). 
A
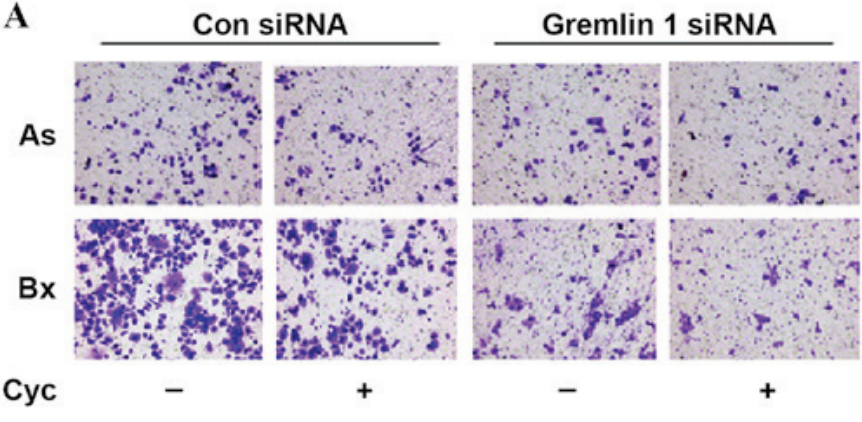

C

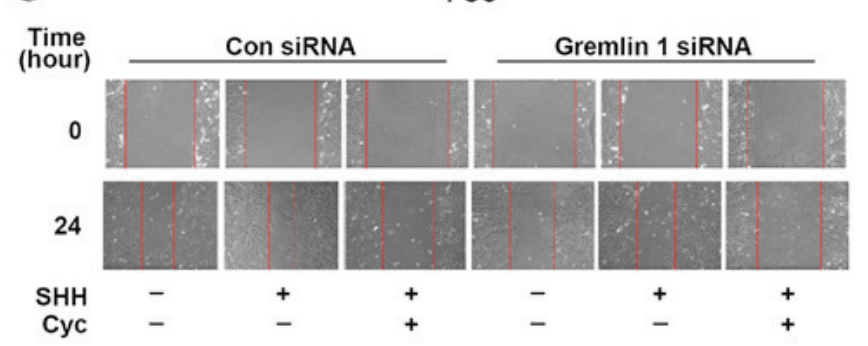

E

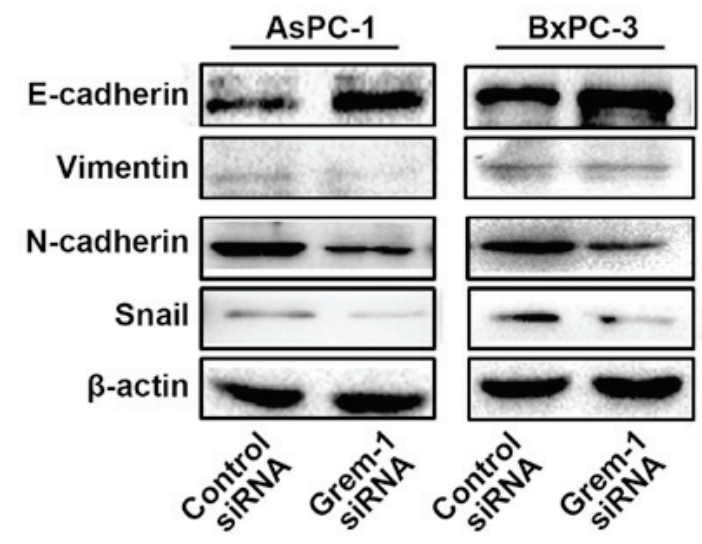

B

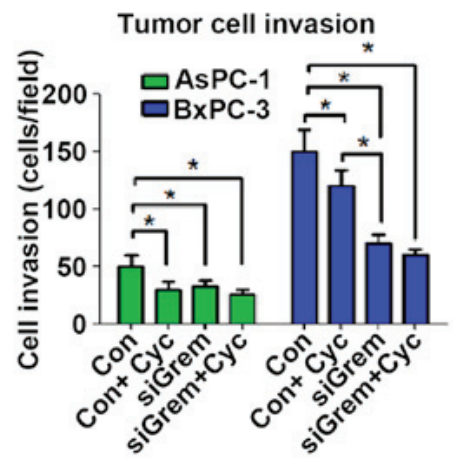

D

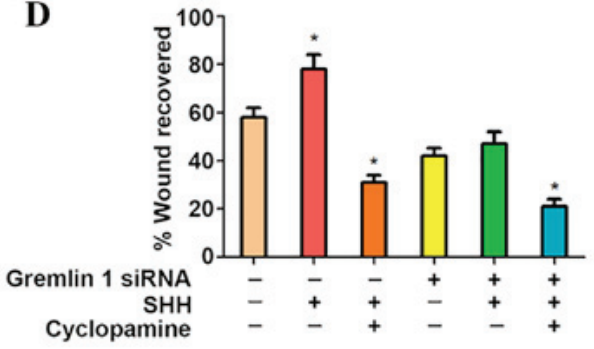

F

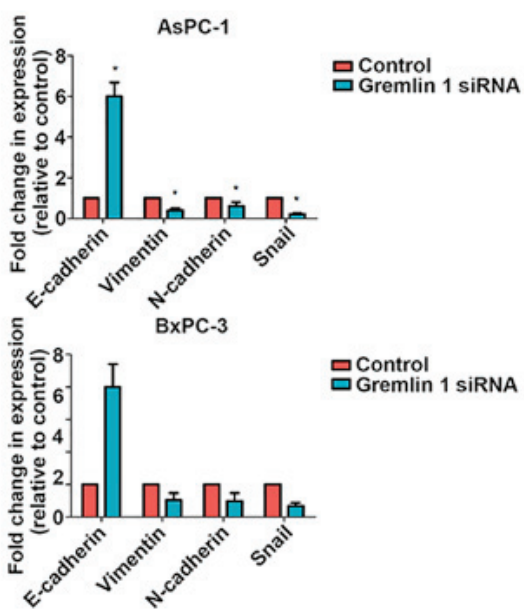

Figure 5. Overexpression of Gremlin 1 induced by SHH signaling promotes the invasion and migration ability of pancreatic cancer cells in vitro. (A) Images (magnification, x200) and (B) quantification of the effect of Gremlin 1 on the invasion of AsPC-1 and BxPC-3 cells. (C) Images (magnification, x200) and (D) quantification of the effect of Gremlin 1 on the migration of PSCs. (E) Blots and (F) quantification showed that Gremlin 1 promoted epithelial to mesenchymal transition in pancreatic cancer cells. SHH, sonic hedgehog; PSCs, pancreatic stellate cells; siRNA, small interfering RNA; Con, control; AS, AsPC-1 cells; Bx, BxPC-3 cells; Cyc, cyclopamine; Grem, Gremlin 1.

Gremlin 1 is important in tumor angiogenesis, involving VEGF receptor (VEGFR)2 signaling. Kim et al also revealed a possible BMP-independent and VEGFR2-independent mechanism of Gremlin 1 during pathogenesis (38). The present study provided evidence that Gremlin 1, which is induced by $\mathrm{SHH}$ signaling, acts as an enhancer for tumor progression in PDAC.

In the present study, weak, but not completely negative, expression of Gremlin 1 was found in the normal pancreas, mainly in islet cells. Gremlin 1 is also known as IHG-2. The name IHG-2 is derived from the finding that the expression of Gremlin 1 in mesangial cells, originating from the glomerular mesangium of the kidney, is promoted by high ambient glucose (5). The positive contribution of BMP signaling to the modulation of insulin secretion indicates that the expression of Gremlin 1 may be a subtle response to the impairment of pancreas islet cells by high glucose during the pathogenesis of diabetes mellitus $(39,40)$. In normal C57 mice, following
8 or 12 weeks of a high-fat diet, which is necessary to impair glucose homeostasis and induce diabetes mellitus, the expression of Gremlin 1 exhibited an increasing trend (41). These findings further support a close association between IHG-2 (Gremlin 1), and high glucose, revealing a novel understanding of the inner mechanism of pancreas islet cells in diabetes mellitus. In previous years, studies have provided support for the connection between diabetes mellitus and pancreatic cancer (42-44). The hypothesis that aberrant insulin regulation is a growth promoter for pancreatic cancer has been substantiated by in vivo and in vitro experiments $(45,46)$. The implication that Gremlin 1 is positively expressed in the islet cells of the normal pancreas, and the role of Gremlin 1 during carcinogenesis from acinar-to-ductal metaplasia to cancer require further investigation.

The histopathological analysis performed in the present study on clinical specimens and orthotopic transplant model 
tissues revealed that Gremlin 1 was predominantly expressed in the stroma, although weak staining in certain cases was found in the parenchyma; and patients with negative Gremlin 1 staining tended to have a higher survival rate. In the pancreatic cancer stroma, desmoplasia is a common pathological feature and is regarded as a promoter of malignant progression (47). This fibrotic response in the tumor stroma regularly involves the activation of PSCs. In vitro, a high expression level of Gremlin 1 was found in activated PSCs. According to previous articles, such a finding is not rare. In the liver, Gremlin 1 is recognized as a marker of hepatic fibrosis as this secretory protein is expressed at a high level in activated hepatic stellate cells and is involved in EMT (49). In the kidney, the expression of Gremlin 1 is considerably higher and is predominantly observed in regions of tubulointerstitial fibrosis and glomerulosclerosis (48-51). In the intestine, stromal Gremlin 1 is regarded as a potential biomarker and a promising drug target of cancer $(52,53)$. In the brain, the knockdown of Gremlin 1 inhibits glioma carcinogenesis (54). In the skin, Gremlin 1 is considered a marker of activated myofibroblasts and the tumor-stromal interface (55). PSCs are a type of myofibroblastlike cell, which are involved in fibrosis and are the main source of the extracellular matrix, which is essential for excessive fibrous tissue (56). Although the traditional view is that PSCs are likely of local origin, an emerging concept is that the bone marrow (BM) is also a source. BM-derived cancer-associated PSCs, with Gremlin 1 as a novel marker (57), are increased when the pancreas regenerates or undergoes carcinogenesis (58-60). These reports support the clinical findings of the present study.

According to the statistical analysis of the clinicopathological features, the present study found that Gremlin 1 was positively correlated with the pT status but not with the pM status. It was observed that Gremlin 1 promoted the migration of PSCs and the invasion and EMT of cancer cells. This result appears paradoxical. Of note, although invasion, migration, and EMT are crucial steps of metastasis, every phrase of metastasis is subject to a multitude of complicated and subtle controls. Certain subtle mechanisms may modulate Gremlin 1-induced metastasis. Despite the pT status referring to the size and direct extent of the primary tumor, this concept contains several vital components, including the infiltration, invasion and destruction of the surrounding tissue. For example, pT3 (7th edition of the TNM staging system) refers to cases where the tumor extends beyond the pancreas, without involvement of the celiac axis or superior mesenteric artery. Therefore, a positive correlation between Gremlin 1 staining and $\mathrm{pT}$ status is reasonable with the findings from the in vitro experiments.

Based on our previous investigations on the SHH pathway, it was hypothesized that there is an association between Gremlin 1 and SHH in the cancer-stroma interaction. In the context of vertebrate limb formation, a network involving $\mathrm{SHH}$ and Gremlin 1 has been identified, in which Gremlin 1 is a downstream factor of the cellular reaction to the $\mathrm{SHH}$ signal depending on Gli-1 (19). Although the FGF-SHH signal is reduced by BMP4, Gremlin 1 maintains the signal by antagonizing BMP4 (19). Therefore, in this positive feedback loop, SHH maintains the expression of Gremlin 1 to reverse the suppressive effects of BMP4 on the expression of FGF4, and the latter factor increasingly upregulates SHH (21).
Accordingly, in $\mathrm{SHH}^{-/-}$mice, Gremlin 1 activation is considerably suppressed in vivo, leading to limb deformation. Similarly, limb deformation is rescued by grafting Gremlin-expressing cells, as Gremlin 1 is a potent promoter of the expression of FGF4 and restores the FGF-SHH feedback loop (17). In addition, Gremlin 1 deletion in genetically modified animals induces irregular BMP4 signaling, which actively suppresses FGF-SHH signaling. However, as limb-bud outgrowth is essentially controlled by signals in this FGF-SHH positive feedback loop, high levels of FGF signaling also trigger the FGF-Gremlin 1 negative feedback loop and, subsequently, inhibiting of the expression of Gremlin $1(6,17)$. Therefore, a subtle balance between the promotion and termination of growth is achieved in organ formation and regeneration, and Gremlin 1 is a critical regulator in this delicate network, although several unidentified molecules may make substantial contributions to this process. In the in vitro experiments in the present study, Gremlin 1 acted as a downstream factor of the cellular reaction to the SHH signal, which correlated with Gli-1. It was confirmed that the two pancreatic cancer cells and activated PSCs expressed Gremlin 1. In addition, extrinsic SHH was a potent trigger causing an increase of Gremlin 1 in the PSCs, whereas this effect was negligible in cancer cells. However, in the present study, the level of Gremlin 1 succumbed to RNA interference-mediated Gli-1 interference on both sides. It has been confirmed that tumor cells secrete $\mathrm{SHH}$, which cannot activate $\mathrm{SHH}$ pathways in tumor cells but instead trigger signaling in stromal cells, including PSCs (14). Therefore, the present study suggested that SHH signaling was crucial for the expression of Gremlin 1 in pancreatic cancer.

In the present study, it was found that Gremlin 1 was not only a promoter of PSC proliferation and migration, but also an enhancer of the proliferation, invasion and EMT of pancreatic cancer cells. Gremlin 1 is involved in EMT in hepatocellular cancer, and additional clues regarding the function of Gremlin 1 have arisen from studies involving the BMP pathway. Initially, Gremlin 1 was recognized as a gene that produces dorsalizing activity via its antagonism of BMP signaling from a screen of a Xenopus cDNA library (9). As with the majority of members of the BMP antagonist family, Gremlin 1 has eight conserved cysteine residues, also known as the eight-membered ring. This structure enables Gremlin 1 to bind BMP molecules tightly and to obstruct the binding site for BMP receptors (3). Active BMP dimers bind certain $\mathrm{BMP}$ receptors on the cell membrane, generating their signal via the phosphorylation of R-Smads and several non-canonical intracellular effectors. The function of BMPs in development and in various diseases is versatile. In the intestine and colon, BMPs inhibit stem cell self-renewal via the inhibition of Wnt signaling (61). A number of these functions are shared among diverse family members, whereas other functions are specific to certain proteins. For example, BMP2/4/7 exert specific effects in a wide variety of manners, including the induction of EMT in several human pancreatic cancer cell lines via the phosphorylation of Smad1 and the upregulation of MMP2 (62). The concentration of active BMPs is critical in controlling their influence $(63,64)$. It has been observed that BMP4 potently reduces the growth of and increases the migration and invasion of pancreatic cancer cells, including Panc-1 and MiaPaCa-2 cells, when its concentration is $250 \mathrm{ng} / \mathrm{ml}(65)$. 
Further investigations have shown that the EMT and migration of Panc-1 cells are triggered when the BMP4 concentration is $\sim 50 \mathrm{ng} / \mathrm{ml}(66,67)$. Such a delicate concentration-dependent mechanism indicates that Gremlin 1, a specific inhibitor that fine-tunes BMP2/4/7 signaling, is effective at exerting a unique effect on the self-renewal, invasion, migration and EMT of pancreatic cancer cells.

Despite the fact that the results of the present study support the hypothesis that Gremlin 1 acts as a downstream factor of SHH signaling and contributes to the progression of pancreatic cancer, details require precise investigation to locate the cellular signaling factors. In addition, the reciprocal interaction network, including FGF4/8, SHH, BMP4 and Gremlin 1, has not been fully examined, and several other factors in the pathogenesis cannot be ruled out. Therefore, SHH-Gremlin 1-associated oncogenesis requires further investigation.

In conclusion, the present study showed that the aberrant expression of Gremlin 1 in the pancreatic cancer microenvironment was induced by $\mathrm{SHH}$ signaling. The data from the in vitro experiments suggest that Gremlin 1 promoted the proliferation and migration of PSCs, and the proliferation, invasion and EMT of pancreatic cancer cells. Collectively, Gremlin 1 may be a therapeutic target and emerging marker of pancreatic cancer.

\section{Acknowledgements}

Not applicable.

\section{Funding}

This study was supported by grants from the National Natural Scientific Foundation of China (grant nos. 81472248, 81502074, 81672434 and 81702916).

\section{Availability of data and materials}

The datasets used and/or analyzed during the current study are available from the corresponding author on reasonable request.

\section{Authors' contributions}

YY, LC, QM and JM designed the experiments; YY and LC carried out the majority of the experiments; BY, CZ and WQ analyzed the data; YX and TQ organized the figures and contributed to the data analysis and interpretation, and the writing and revision of the manuscript; YC and LH wrote the manuscript and help performed the immunohistochemistry experiments; QM and JM reviewed it.

\section{Ethics approval and consent to participate}

The study was approved by the Ethical Committees of Shaanxi Provincial People's Hospital and the First Affiliated Hospital of Xi'an Jiaotong University. Each patient signed an informed consent form.

\section{Patient consent for publication}

Not applicable.

\section{Competing interests}

The authors declare that they have no competing interests.

\section{References}

1. Siegel RL, Miller KD and Jemal A: Cancer Statistics, 2017. CA Cancer J Clin 67: 7-30, 2017.

2. Chen W, Zheng R, Baade PD, Zhang S, Zeng H, Bray F, Jemal A, Yu XQ and He J: Cancer statistics in China, 2015. CA Cancer J Clin 66: 115-132, 2016.

3. Nolan K, Kattamuri C, Luedeke DM, Deng X, Jagpal A, Zhang F, Linhardt RJ, Kenny AP, Zorn AM and Thompson TB: Structure of protein related to Dan and Cerberus: Insights into the mechanism of bone morphogenetic protein antagonism. Structure 21: 1417-1429, 2013.

4. Chen B, Blair DG, Plisov S, Vasiliev G, Perantoni AO, Chen Q, Athanasiou M, Wu JY, Oppenheim JJ and Yang D: Cutting edge: Bone morphogenetic protein antagonists Drm/Gremlin and Dan interact with Slits and act as negative regulators of monocyte chemotaxis. J Immunol 173: 5914-5917, 2004.

5. McMahon R, Murphy M, Clarkson M, Taal M, Mackenzie HS, Godson C, Martin F and Brady HR: IHG-2, a mesangial cell gene induced by high glucose, is human gremlin. Regulation by extracellular glucose concentration, cyclic mechanical strain, and transforming growth factor-beta1. J Biol Chem 275: 9901-9904, 2000.

6. Walsh DW, Godson C, Brazil DP and Martin F: Extracellular BMP-antagonist regulation in development and disease: Tied up in knots. Trends Cell Biol 20: 244-256, 2010.

7. Li Q, Huo Y, Guo Y, Zheng X, Sun W and Hao Z: Generation and applications of a DNA aptamer against Gremlin-1. Molecules 22: 22, 2017.

8. Topol LZ, Modi WS, Koochekpour S and Blair DG: DRM/ GREMLIN (CKTSF1B1) maps to human chromosome 15 and is highly expressed in adult and fetal brain. Cytogenet Cell Genet 89: 79-84, 2000.

9. Hsu DR, Economides AN, Wang X, Eimon PM and Harland RM: The Xenopus dorsalizing factor Gremlin identifies a novel family of secreted proteins that antagonize BMP activities. Mol Cell 1: 673-683, 1998.

10. Topol LZ, Bardot B, Zhang Q, Resau J, Huillard E, Marx M, Calothy G and Blair DG: Biosynthesis, post-translation modification, and functional characterization of Drm/Gremlin. J Biol Chem 275: 8785-8793, 2000.

11. Sneddon JB, Zhen HH, Montgomery K, van de Rijn M, Tward AD, West R, Gladstone H, Chang HY, Morganroth GS, Oro AE, et al: Bone morphogenetic protein antagonist Gremlin 1 is widely expressed by cancer-associated stromal cells and can promote tumor cell proliferation. Proc Natl Acad Sci USA 103: 14842-14847, 2006.

12. Thayer SP, di Magliano MP, Heiser PW, Nielsen CM, Roberts DJ, Lauwers GY, Qi YP, Gysin S, Fernández-del Castillo C, Yajnik V, et al: Hedgehog is an early and late mediator of pancreatic cancer tumorigenesis. Nature 425: 851-856, 2003.

13. Feldmann G, Dhara S, Fendrich V, Bedja D, Beaty R, Mullendore M, Karikari C, Alvarez H, Iacobuzio-Donahue C, Jimeno A, et al: Blockade of hedgehog signaling inhibits pancreatic cancer invasion and metastases: A new paradigm for combination therapy in solid cancers. Cancer Res 67: 2187-2196, 2007.

14. Li X, Wang Z, Ma Q, Xu Q, Liu H, Duan W, Lei J, Ma J, Wang X, Lv S, et al: Sonic hedgehog paracrine signaling activates stromal cells to promote perineural invasion in pancreatic cancer. Clin Cancer Res 20: 4326-4338, 2014.

15. Islam SS, Mokhtari RB, Noman AS, Uddin M, Rahman MZ, Azadi MA, Zlotta A, van der Kwast T, Yeger H and Farhat WA: Sonic hedgehog (Shh) signaling promotes tumorigenicity and stemness via activation of epithelial-to-mesenchymal transition (EMT) in bladder cancer. Mol Carcinog 55: 537-551, 2016.

16. Yauch RL, Gould SE, Scales SJ, Tang T, Tian H, Ahn CP, Marshall D, Fu L, Januario T, Kallop D, et al: A paracrine requirement for hedgehog signalling in cancer. Nature 455: 406-410, 2008

17. Verheyden JM and Sun X: An Fgf/Gremlin inhibitory feedback loop triggers termination of limb bud outgrowth. Nature 454: 638-641, 2008 
18. Panman L, Galli A, Lagarde N, Michos O, Soete G, Zuniga A and Zeller R: Differential regulation of gene expression in the digit forming area of the mouse limb bud by $\mathrm{SHH}$ and Gremlin 1/FGF-mediated epithelial-mesenchymal signalling. Development 133: 3419-3428, 2006.

19. Zúñiga A, Haramis AP, McMahon AP and Zeller R: Signal relay by BMP antagonism controls the SHH/FGF4 feedback loop in vertebrate limb buds. Nature 401: 598-602, 1999.

20. Niswander L, Jeffrey S, Martin GR and Tickle C: A positive feedback loop coordinates growth and patterning in the vertebrate limb. Nature 371: 609-612, 1994.

21. Bénazet J-D, Bischofberger M, Tiecke E, Gonçalves A, Martin JF, Zuniga A, Naef F and Zeller R: A self-regulatory system of interlinked signaling feedback loops controls mouse limb patterning Science 323: 1050-1053, 2009.

22. Cao L, Xiao X, Lei J, Duan W, Ma Q and Li W: Curcumin inhibits hypoxia-induced epithelial mesenchymal transition in pancreatic cancer cells via suppression of the hedgehog signaling pathway. Oncol Rep 35: 3728-3734, 2016.

23. Li W, Cao L, Chen X, Lei J and Ma Q: Resveratrol inhibits hypoxia-driven ROS-induced invasive and migratory ability of pancreatic cancer cells via suppression of the Hedgehog signaling pathway. Oncol Rep 35: 1718-1726, 2016.

24. Edge SB and Compton CC: The American Joint Committee on Cancer: The 7th edition of the AJCC cancer staging manual and the future of TNM. Ann Surg Oncol 17: 1471-1474, 2010.

25. Vonlaufen A, Phillips PA, Yang L, Xu Z, Fiala-Beer E, Zhang X, Pirola RC, Wilson JS and Apte MV: Isolation of quiescent human pancreatic stellate cells: A promising in vitro tool for studies of human pancreatic stellate cell biology. Pancreatology 10: 434-443, 2010

26. Han L, Ma J, Duan W, Zhang L, Yu S, Xu Q, Lei J, Li X, Wang Z, Wu Z, et al: Pancreatic stellate cells contribute pancreatic cancer pain via activation of $\mathrm{sHH}$ signaling pathway. Oncotarget 7: 18146-18158, 2016.

27. Jiang Z, Chen X, Chen K, Sun L, Gao L, Zhou C, Lei M, Duan W, Wang Z, Ma Q, et al: YAP Inhibition by Resveratrol via Activation of AMPK Enhances the Sensitivity of Pancreatic Cancer Cells to Gemcitabine. Nutrients 8: 8, 2016.

28. Livak KJ and Schmittgen TD: Analysis of relative gene expression data using real-time quantitative PCR and the 2(-DeltaDeltaC(T)) method. Methods 25: 402-408, 2001.

29. Lei J, Ma J, Ma Q, Li X, Liu H, Xu Q, Duan W, Sun Q, Xu $\mathrm{J}, \mathrm{Wu} \mathrm{Z}$, et al: Hedgehog signaling regulates hypoxia induced epithelial to mesenchymal transition and invasion in pancreatic cancer cells via a ligand-independent manner. Mol Cancer 12. 66-66, 2013.

30. Li X, Ma Q, Xu Q, Liu H, Lei J, Duan W, Bhat K, Wang F, Wu E and Wang Z: SDF-1/CXCR4 signaling induces pancreatic cancer cell invasion and epithelial-mesenchymal transition in vitro through non-canonical activation of Hedgehog pathway. Cancer Lett 322: 169-176, 2012.

31. Segara D, Biankin AV, Kench JG, Langusch CC, Dawson AC Skalicky DA, Gotley DC, Coleman MJ, Sutherland RL and Henshall SM: Expression of HOXB2, a retinoic acid signaling target in pancreatic cancer and pancreatic intraepithelial neoplasia. Clin Cancer Res 11: 3587-3596, 2005.

32. Iacobuzio-Donahue CA, Maitra A, Olsen M, Lowe AW, van Heek NT, Rosty C, Walter K, Sato N, Parker A, Ashfaq R, et al: Exploration of global gene expression patterns in pancreatic adenocarcinoma using cDNA microarrays. Am J Pathol 162: 1151-1162, 2003.

33. Koli K, Sutinen E, Rönty M, Rantakari P, Fortino V,Pulkkinen V, Greco D, Sipilä P and Myllärniemi M: Gremlin-1 overexpression in mouse lung reduces silica-induced lymphocyte recruitment - A link to idiopathic pulmonary fibrosis through negative correlation with CXCL10 chemokine. PLoS One 11: e0159010, 2016.

34. Namkoong H, Shin SM, Kim HK, Ha SA, Cho GW, Hur SY, Kim TE and Kim JW: The bone morphogenetic protein antagonist Gremlin 1 is overexpressed in human cancers and interacts with YWHAH protein. BMC Cancer 6: 74-74, 2006.

35. Karagiannis GS, Musrap N, Saraon P, Treacy A, Schaeffer DF, Kirsch R, Riddell RH and Diamandis EP: Bone morphogenetic protein antagonist gremlin-1 regulates colon cancer progression. Biol Chem 396: 163-183, 2015.

36. Piccirillo SG, Reynolds BA, Zanetti N, Lamorte G, Binda E, Broggi G, Brem H, Olivi A, Dimeco F and Vescovi AL: Bone morphogenetic proteins inhibit the tumorigenic potential of human brain tumour-initiating cells. Nature 444: 761-765, 2006.
37. Maciel TT, Melo RS, Schor N and Campos AH: Gremlin promotes vascular smooth muscle cell proliferation and migration. J Mol Cell Cardiol 44: 370-379, 2008.

38. Kim M, Yoon S, Lee S, Ha SA, Kim HK, Kim JW and Chung J: Gremlin-1 induces BMP-independent tumor cell proliferation, migration, and invasion. PLoS One 7: e35100, 2012.

39. Goulley J, Dahl U, Baeza N, Mishina Y and Edlund H: BMP4-BMPR1A signaling in $\beta$ cells is required for and augments glucose-stimulated insulin secretion. Cell Metab 5: 207-219, 2007.

40. Scott GJ, Ray MK, Ward T, McCann K, Peddada S, Jiang FX and Mishina Y: Abnormal glucose metabolism in heterozygous mutant mice for a type I receptor required for BMP signaling. Genesis 47: 385-391, 2009.

41. Henley KD, Gooding KA, Economides AN and Gannon M: Inactivation of the dual Bmp/Wnt inhibitor Sostdc1 enhances pancreatic islet function. Am J Physiol Endocrinol Metab 303: E752-E761, 2012.

42. Eibl G, Cruz-Monserrate Z, Korc M, Petrov MS, Goodarzi MO, Fisher WE, Habtezion A, Lugea A, Pandol SJ, Hart PA, et al: Diabetes mellitus and obesity as risk factors for pancreatic cancer. J Acad Nutr Diet 118: 555-567, 2017.

43. Kleeff J, Costello E, Jackson R, Halloran C, Greenhalf W, Ghaneh P, Lamb RF, Lerch MM, Mayerle J, Palmer D, et al: The impact of diabetes mellitus on survival following resection and adjuvant chemotherapy for pancreatic cancer. Br J Cancer 115: 887-894, 2016.

44. Hart PA, Law RJ, Frank RD, Bamlet WR, Burch PA, Petersen GM, Rabe KG and Chari ST: Impact of diabetes mellitus on clinical outcomes in patients undergoing surgical resection for pancreatic cancer: A retrospective, cohort study. Am J Gastroenterol 109: 1484-1492, 2014.

45. Chen K, Qian W, Jiang Z, Cheng L, Li J, Sun L, Zhou C, Gao L, Lei M, Yan B, et al: Metformin suppresses cancer initiation and progression in genetic mouse models of pancreatic cancer. Mol Cancer 16: 131, 2017.

46. Duan W, Chen K, Jiang Z, Chen X, Sun L, Li J, Lei J, Xu Q, Ma J, Li X, et al: Desmoplasia suppression by metformin-mediated AMPK activation inhibits pancreatic cancer progression. Cancer Lett 385: 225-233, 2017.

47. Liu J, Zhong Y, Liu G, Zhang X, Xiao B, Huang S, Liu H and He L: Role of Stat3 Signaling in Control of EMT of Tubular Epithelial Cells During Renal Fibrosis. Cell Physiol Biochem 42: 2552-2558, 2017.

48. Roxburgh SA, Murphy M, Pollock CA and Brazil DP: Recapitulation of embryological programmes in renal fibrosis-the importance of epithelial cell plasticity and developmental genes. Nephron, Physiol 103: 139-148, 2006.

49. Walsh DW, Roxburgh SA, McGettigan P, Berthier CC, Higgins DG, Kretzler M, Cohen CD, Mezzano S, Brazil DP and Martin F: Co-regulation of Gremlin and Notch signalling in diabetic nephropathy. Biochim Biophys Acta 1782: 10-21, 2008.

50. Dolan V, Murphy M, Sadlier D, Lappin D, Doran P, Godson C, Martin F, O'Meara Y, Schmid H, Henger A, et al: Expression of gremlin, a bone morphogenetic protein antagonist, in human diabetic nephropathy. Am J Kidney Dis 45: 1034-1039, 2005.

51. McKnight AJ, Patterson CC, Pettigrew KA, Savage DA, Kilner J, Murphy M, Sadlier D and Maxwell AP; Warren 3/U.K. Genetics of Kidneys in Diabetes (GoKinD) Study Group: A GREM1 gene variant associates with diabetic nephropathy. J Am Soc Nephrol 21: 773-781, 2010.

52. Jang BG, Kim HS, Chang WY, Bae JM, Oh HJ, Wen X, Jeong S, Cho NY, Kim WH and Kang GH: Prognostic significance of stromal GREM1 expression in colorectal cancer. Hum Pathol 62: 56-65, 2017.

53. Pelli A, Väyrynen JP, Klintrup K, Mäkelä J, Mäkinen MJ, Tuomisto A and Karttunen TJ: Gremlin1 expression associates with serrated pathway and favourable prognosis in colorectal cancer. Histopathology 69: 831-838, 2016.

54. Guan Y, Cheng W, Zou C, Wang T, Cao Z and Wu A: Gremlin1 promotes carcinogenesis of glioma in vitro. Clin Exp Pharmacol Physiol 44: 244-256, 2017.

55. Kim HS, Shin MS, Cheon MS, Kim JW, Lee C, Kim WH, Kim YS and Jang BG: GREM1 is expressed in the cancer-associated myofibroblasts of basal cell carcinomas. PLoS One 12: e0174565, 2017.

56. Koikawa K, Ohuchida K, Takesue S, Ando Y, Kibe S, Nakayama H, Endo S, Abe T, Okumura T, Horioka K, et al: Pancreatic stellate cells reorganize matrix components and lead pancreatic cancer invasion via the function of Endo180. Cancer Lett 412: 143-154, 2018. 
57. Quante M, Tu SP, Tomita H, Gonda T, Wang SS, Takashi S, Baik GH, Shibata W, Diprete B, Betz KS, et al: Bone marrowderived myofibroblasts contribute to the mesenchymal stem cell niche and promote tumor growth. Cancer Cell 19: 257-272, 2011.

58. Ishii G, Sangai T, Oda T, Aoyagi Y, Hasebe T, Kanomata N, Endoh Y, Okumura C, Okuhara Y, Magae J, et al: Bone-marrowderived myofibroblasts contribute to the cancer-induced stromal reaction. Biochem Biophys Res Commun 309: 232-240, 2003.

59. Marrache F, Pendyala S, Bhagat G, Betz KS, Song Z and Wang TC: Role of bone marrow-derived cells in experimental chronic pancreatitis. Gut 57: 1113-1120, 2008.

60. Scarlett CJ: Contribution of bone marrow derived cells to the pancreatic tumor microenvironment. Front Physiol 4: 56-56, 2013.

61. Kosinski C, Li VS, Chan ASY, Zhang J, Ho C, Tsui WY, Chan TL, Mifflin RC, Powell DW, Yuen ST, et al: Gene expression patterns of human colon tops and basal crypts and BMP antagonists as intestinal stem cell niche factors. Proc Natl Acad Sci USA 104: 15418-15423, 2007.

62. Gordon KJ, Kirkbride KC, How T and Blobe GC: Bone morphogenetic proteins induce pancreatic cancer cell invasiveness through a Smad1-dependent mechanism that involves matrix metalloproteinase-2. Carcinogenesis 30: 238-248, 2009.
63. Yin Y, Yang $Y$, Yang L, Yang Y, Li C, Liu X and Qu Y: Overexpression of Gremlin promotes non-small cell lung cancer progression. Tumour Biol 37: 2597-2602, 2016.

64. Wellbrock J, Sheikhzadeh S, Oliveira-Ferrer L, Stamm H, Hillebrand M, Keyser B, Klokow M, Vohwinkel G, Bonk V, Otto B, et al: Overexpression of Gremlin-1 in patients with Loeys-Dietz syndrome: Implications on pathophysiology and early disease detection. PLoS One 9: e104742, 2014.

65. Virtanen S, Alarmo EL, Sandström S, Ampuja $M$ and Kallioniemi A: Bone morphogenetic protein -4 and -5 in pancreatic cancer--novel bidirectional players. Exp Cell Res 317: 2136-2146, 2011.

66. Hamada S, Satoh K, Hirota M, Kimura K, Kanno A, Masamune A and Shimosegawa $\mathrm{T}$ : Bone morphogenetic protein 4 induces epithelial-mesenchymal transition through MSX2 induction on pancreatic cancer cell line. J Cell Physiol 213: 768-774, 2007.

67. Kallioniemi A: Bone morphogenetic protein 4-a fascinating regulator of cancer cell behavior. Cancer Genet 205: 267-277, 2012.

This work is licensed under a Creative Commons Attribution-NonCommercial-NoDerivatives 4.0 International (CC BY-NC-ND 4.0) License. 